\title{
CDC Guidelines: Be Careful What You Wish For
}

\section{Sanford M. Silverman, MD}

In 2016, the Centers for Disease Control (CDC) published guidelines for the treatment of chronic non-cancer pain with opioid therapy. The scope of the guidelines included primary care physicians treating chronic pain defined $>3$ months in duration, which excluded active cancer treatment, end-of-life, palliative care, and age $<18$ years.

The rationale for these guidelines was that:

"Primary care clinicians report having concerns about opioid pain medication misuse, find managing patients with chronic pain stressful, express concern about patient addiction, and report insufficient training in prescribing opioids. In addition, across medical specialties it is believed that addiction is a common consequence of prolonged use, and that long-term opioid therapy often is overprescribed for patients with chronic non-cancer pain (1)."

In 2012, 259 million opioid prescriptions were written in the United States. Prescription drug abuse was considered the fastest growing drug problem in the US. According to a CDC report, enough opioid pain relievers were sold in $\mathbf{2 0 1 0}$ to "medicate every adult in the United States with the equivalent of a typical dose of $5 \mathrm{mg}$ of hydrocodone every 4 hours for one month (2)."

In $2014,47,055$ persons in the US died from prescription drug overdose, 18,893 of those from prescription opioid overdose $(3,4)$.

Since the publication of these guidelines, many physicians have altered their practice regarding the prescribing opioids. The guidelines were intended

Author for correspondence: Sanford M. Silverman, MD

Address: 8130 Glades Road \#386, Boca Raton, FL 33434

E-mail: sanfordsilverman@cpmedicine.com

Conflict of interest: Dr. Silverman is a speaker and receives honoraria for promotional programs for the following companies: Purdue Pharma, Depomed, Daiichi Sankyo, BioDelivery Sciences International (BDSI), and Astra Zeneca. for primary care physicians but have been applied to all physicians (to include pain management specialists) by insurers, regulatory agencies, and state legislatures.

Since publication of the guidelines, the CDC (July 2017) reported that between 2006 and 2015 the amount of opioids prescribed in the United States peaked in 2010 at 782 morphine milligram equivalents (MME) per capita and then decreased each year through 2015 to 640 MME per capita. Prescribing rates increased from 72.4 to 81.2 prescriptions per 100 persons between 2006 and 2010 , were constant between 2010 and 2012, and then declined to 70.6 per 100 persons from 2012 to 2015 , a $13.1 \%$ decline. Despite the decline, the amount of opioids prescribed in 2015 remained more than 3 times higher than it was in 1999. In addition, it was nearly 4 times higher than in Europe in 2015 (2). Overall, overdose deaths by commonly prescribed opioids are on the decline while deaths from heroin with fentanyl are rapidly rising (Fig. 1).

In addition, the CDC believes illicit drug overdose and high levels of prescription opioid use are related. In Rhode Island, 24 of 69 people who died from il-

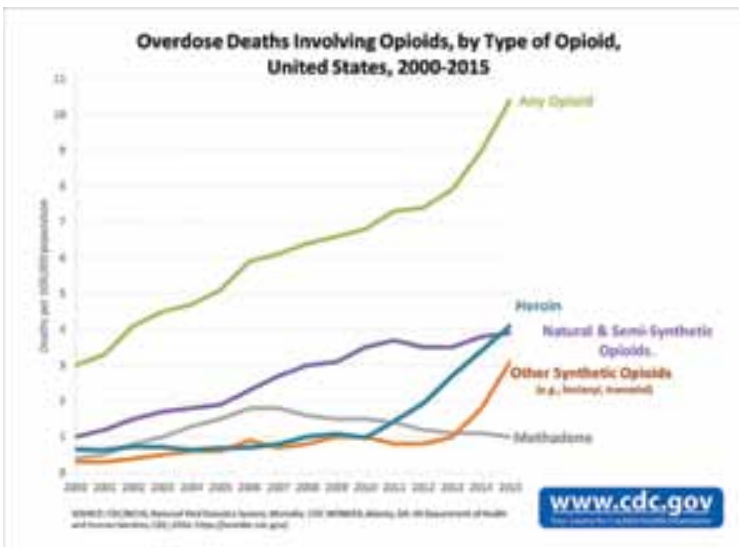

Fig. 1. Overdose deaths by opioid type. 
licit fentanyl overdoses from January 2012 to March 2014 had filled an opioid prescription within 90 days of death (5). A 2017 report from the CDC examined how patients taking painkillers respond to prescriptions of varying lengths. If a patient is initially given a one-day supply, his likelihood of still using the drug a year later is about $6 \%$. That number rises to roughly $10 \%$ for patients given a 2 -day supply and $45 \%$ for a 40-day prescription (6).

However, these numbers are refuted by other studies $(7,8)$ which state that the highest predictors of substance abuse are a family history of such or concurrent overuse of alcohol. The fact that persons had filled an opioid prescription within 90 days does not establish correlation with causation; they simply show numbers.

Another factor which is frequently ignored is the occurrence of polypharmacy in most drug overdoses. Approximately $30 \%$ of non-cancer pain patients are concurrently prescribed benzodiazepines and opioids (9) and approximately $40-60 \%$ is abusing the benzodiazepines, usually taking them an hour after the opioid to "augment" the effect (10). The overdose rate is over twice that for combinations of benzodiazepines and opioids than with either one alone (Fig. 2).

In addition, benzodiazepines and opioids continue to be problematic since many chronic pain patients are forced to receive them from 2 separate prescribers, thus increasing the costs of medical office visits and drug testing. This also increases the liability for each prescriber in the event of an overdose.

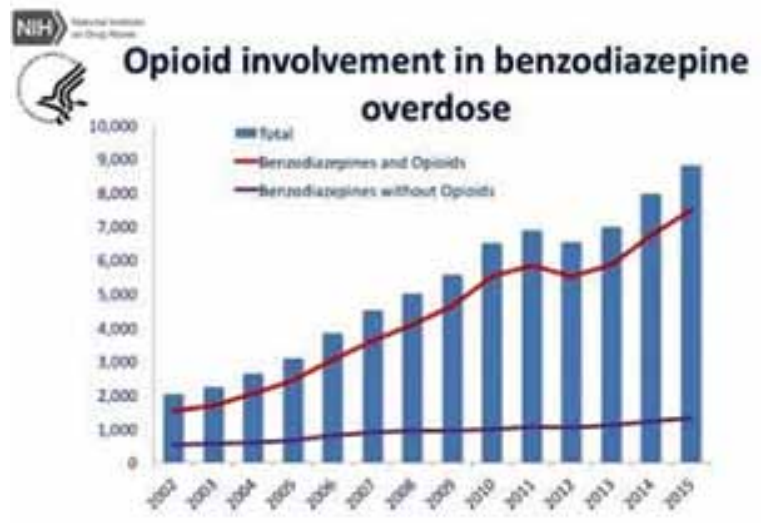

Fig. 2. Overdose deaths involving opioids and benzodiazepines.
Benzodiazepines in fact show very little evidence in the successful treatment of anxiety disorders, whereas antidepressant agents are the drugs of choice, particularly agents such as the newer selective serotonin reuptake inhibitors and selective norepinephrine reuptake inhibitors, which have a safer adverse effect profile and higher ease of use than the older tricyclic antidepressants (11).

Methadone accounted for approximately $1 \%$ of all opioid prescriptions, and overall, methadone-related deaths accounted for $22.9 \%$ of all opioid-related mortalities in 2014 ( Fig. 3). Its unpredictable, long half-life and incomplete cross tolerance makes methadone difficult to use especially during opioid rotation.

In addition, the death rate and number of deaths due to heroin and synthetic opioids (fentanyl mixed with heroin) significantly exceeds that of commonly prescribed opioids (Fig. 4).

In the state of Florida, where I practice, prescription opioid abuse was rampant from 1998-2012 and accounted for 6.8 deaths per day at its peak in 2008. Deaths from prescription opioids have significantly reduced due to successful legislation. Unfortunately, deaths from heroin and fentanyl now plague the state. The Broward County Medical Examiner states "We almost never see prescription overdose deaths, they are almost always heroin and fentanyl." In addition, he states "It is impossible to state that an overdose was caused by one entity especially if that overdose shows multiple substances on fluid testing. The only way to state that is if only one substance is found (12)."

The CDC overdose data may be suspect in that it is difficult, if not impossible, to sort out the cause of death from multiple substances. Opioids may be involved in these deaths stated by the CDC, but are not necessarily the cause. It is also clear from the data, the major contributor to opioid overdose deaths is illicit heroin mixed with fentanyl. Nevertheless, legislation continues to focus on reducing the supply of prescription opioids.

\section{Do we have one epidemic or 2?}

The prescription opioid abuse numbers have been delineated above. However, for chronic pain the numbers have largely been ignored:

- In the US, > 100 million people suffer from chronic 


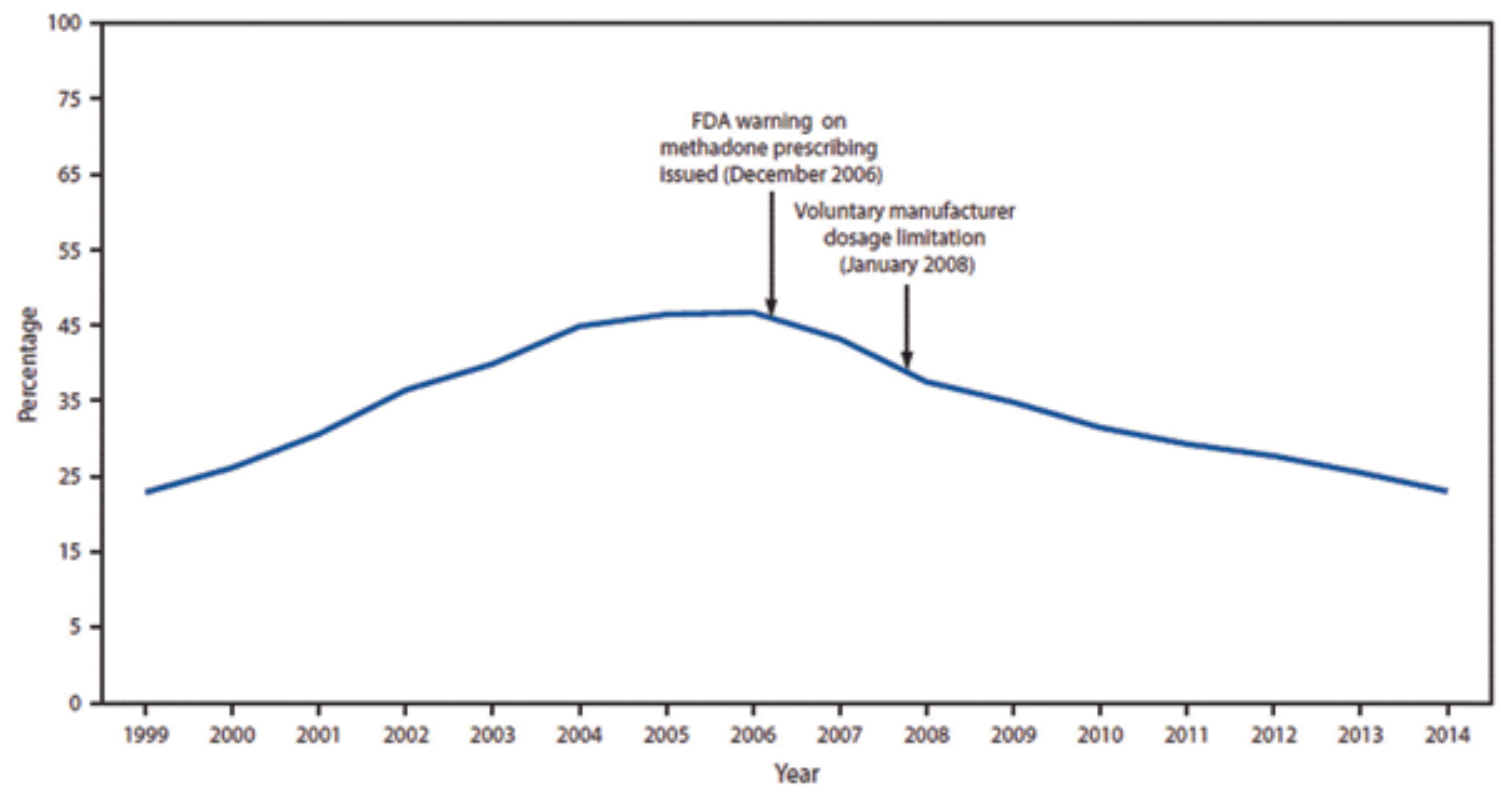

Fig. 3. Overdose deaths caused by methadone as percentage.

pain, 25-39 million with daily chronic pain, 10 million disabled, although quite variable depending upon source (13)

- Significant cost range depending on source ranging from $\$ 100$ billion to $\$ 635$ billion $(14,15)$

- Suicide risk doubled

- 42,773 suicide deaths in 2014 (16)

- 28,000 of those were people with chronic pain.

How do people die of opioid overdoses?

- Accidental, during self-medication or recreational use.

- Therapeutic misadventure (one or more of the following).

- Dose too high.

- Comorbid medical conditions.

- Combination with other prescribed medications.

- Combination with over-thecounter medications.

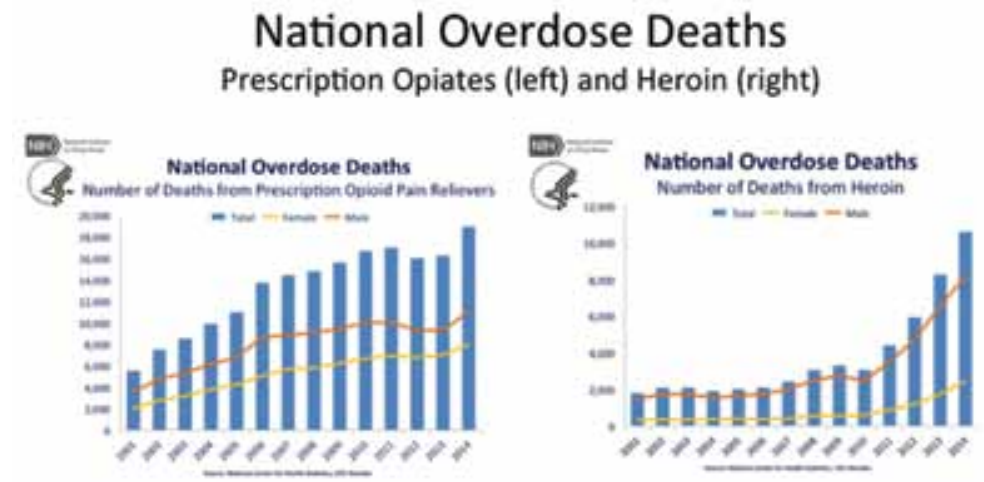

Fig. 4. Overdose deaths from prescription opioids vs. heroin.

- Combination with alcohol.

- Combination with illicit drugs.

- Prescription medications obtained illicitly.

- Schedule I controlled substances.

- Homicide (rare).

- Suicide (not so rare).

Who dies of prescription opioid overdoses?

- People without a prescription for those opioids.

- Some who alter the route of administration (inject, snort, smoke).

- Some who take them orally, with or without other drugs. 
- People with a prescription for those opioids.

- Some who alter the route of administration.

- Some who take them orally, but with other drugs or otherwise not as directed.

- Some who take them exactly as intended.

\section{How many of the 18,893 deaths a year fall into each category? No one knows...}

Several organizations such as the American Pain Society, American Academy of Pain Medicine, the Veterans Administration, Washington State, and the American Society of Interventional Pain Physicians (ASIPP) have developed their own versions of opioid guidelines. Guidelines are simply a set of recommendations based on the best level of evidence. Unfortunately, it appears that most insurers, legislators, and physicians themselves believe that we cannot self-regulate our own behavior and therefore, laws and regulations must be imposed on us to curb our prescribing habits. The easiest way to do this is to limit the number of opioids prescribed, usually by statute or via insurance limits. This regulation is based on the CDC guidelines.

The maximum recommended daily MME number quoted by the CDC is similar to that recommended by ASIPP and the other organizations mentioned above. However, this number was derived from several observational, retrospective studies, which by all accounts are of low-level evidence (17-19). In addition, the recommendations for the initial supply of opioids for acute pain and to initiate opioid therapy with short-acting opioids rather than extended-release/sustained-released opioids are based on poor levels of evidence. It should be noted that all 12 recommendations are based on low-level evidence (levels 3-4) except for recommendation \#12, which recommends medication-assisted treatment with buprenorphine (level 2).

\section{Recommendation \#4 states:}

When starting opioid therapy for chronic pain, clinicians should prescribe immediate-release opioids instead of extended-release/long-acting (ER/LA) opioids.

(Evidence level 4; indicates that one has very little confidence in the effect estimate, and the true effect is likely to be substantially different from the estimate of the effect. Clinical experience and observations, observational studies with important limitations, or randomized clinical trials with several major limitations.)

\section{Recommendation \#5 states:}

When opioids are started, clinicians should prescribe the lowest effective dosage. Clinicians should use caution when prescribing opioids at any dosage, should carefully reassess evidence of individual benefits and risks when increasing dosage to $\geq 50$ $\mathrm{MME} / \mathrm{day}$, and should avoid increasing dosage to $\geq$ $90 \mathrm{MME} /$ day or carefully justify a decision to titrate dosage to $\geq 90 \mathrm{MME} /$ day.

(Evidence level 3; means that confidence in the effect estimate is limited and the true effect might be substantially different from the estimate of the effect. Observational studies or randomized clinical trials with notable limitations)

\section{Recommendation \#6 states:}

Long-term opioid use often begins with treatment of acute pain. When opioids are used for acute pain, clinicians should prescribe the lowest effective dose of immediate-release opioids and should prescribe no greater quantity than needed for the expected duration of pain severe enough to require opioids. Three days or less will often be sufficient; more than 7 days will rarely be needed (evidence level 4).

Regarding recommendation \#5, the phrase or carefully justify a decision to titrate dosage to greater than or equal to $90 \mathrm{MME} /$ day has been largely ignored by insurers and state legislatures. For example, United Healthcare limits the amount of Xtampza ER (Collegium Pharmaceutical Inc., Canton, MA), an abusedeterrent oxycodone product, to $54 \mathrm{mg}$ per day which translates to approximately $100 \mathrm{MME} /$ day (20).

The opioid conversions used by the CDC may be questioned as well (Table 1 ). With respect to methadone, $40 \mathrm{mg}$ equals $320 \mathrm{MME}$, where as 45 mg equals $450 \mathrm{MME}$. Opioid conversion tables are notoriously inaccurate, were developed based on acute pain, and do not account for incomplete cross tolerance. Hence, caution is advised when rotating from one opioid to another. 
The following states now impose limitations on prescribers as follows:

\section{Maine}

> Limited to $100 \mathrm{MME}$ of opioid medication per day, with exceptions for cancer patients, those in palliative and hospice care, and other special circumstances

\section{Rhode Island}

$>$ Initial prescriptions for acute pain to be limited to 20 doses and no more than 30 MME per day

$>$ Prohibiting LA or ER opioids for initial prescriptions for acute pain.

The states of Georgia, Hawaii, Indiana, Oregon, Washington, North Carolina, Ohio, Delaware, New Jersey, Connecticut, New York, Pennsylvania, Massachusetts, Connecticut, and Virginia all limit initial opioid supply between 3-7 days. Florida has proposed legislation to limit initial supply to 3 days.

CVS Health recently announced similar limits in opioid dispensing. Beginning in February of 2018, the program will limit an initial opioid supply to 7 days for acute pain. It also will limit daily dosages and require that immediate-release formulations of drugs be given before ER versions are prescribed. Based on the CDC's recommendations, CVS's new daily dosage limit will be 90 MME daily.

I represented ASIPP on the stakeholder review group for the CDC guidelines. ASIPP was given an opportunity to provide input regarding the 12 recommendations and accepted the recommendations regarding MME, but did not agree with the daily limitations on initial opioid prescribing. Furthermore, ASIPP requested that interventional pain medicine (IPM) be included in recommendation \#1, which suggests that initially, non-pharmacologic therapy should be considered when treating chronic pain. The original recommendation was limited to physical therapy and cognitive behavioral therapy. In the discussion section of the final version of recommendation \#1, IPM was negatively portrayed:

"Interventional approaches such as arthrocentesis and intraarticular glucocorticoid injection for pain associated with rheumatoid arthritis or osteoarthritis and subacromial corticosteroid injection for rotator cuff disease can provide short-term improvement in pain and function. Evidence is insufficient to determine the extent to which repeated glucocorticoid injection
Table 1. CDC opioid conversion table.

\begin{tabular}{|l|c|}
\hline \multicolumn{1}{|c|}{ Opioid } & Conversion Factor \\
\hline Codeine & 0.15 \\
\hline Fentanyl transdermal (in mcg/hr) & 2.4 \\
\hline Hydrocodone & 1 \\
\hline Hydromorphone & 4 \\
\hline Methadone & \\
\hline $1-20 \mathrm{mg} /$ day & 4 \\
\hline $21-40 \mathrm{mg} /$ day & 8 \\
\hline $41-60 \mathrm{mg} /$ day & 10 \\
\hline$\geq 61-80 \mathrm{mg} /$ day & 12 \\
\hline Morphine & 1 \\
\hline Oxycodone & 1.5 \\
\hline Oxymorphone & 3 \\
\hline Tapentadol & 0.4 \\
\hline
\end{tabular}

increases potential risks such as articular cartilage changes (in osteoarthritis) and sepsis. Serious adverse events are rare but have been reported with epidural injection."

In 2015, I presented the CDC guidelines at the ASIPP annual meeting. Comments from the audience were varied but mostly members voiced support for the guidelines. Statements such as "we really needed these" and "it's about time this was done" were common. These statements suggest that those physicians believe we cannot self-regulate but must have rules and statutes imposed upon us. The CDC guidelines are simply a set of 12 recommendations designed for primary care physicians for the initiation of opioid therapy. They were not designed for pain specialists nor do they address patients who already receive opioids for chronic pain. Clearly, the imposition of the guidelines suggests that physicians cannot selfregulate prescribing behavior. This unfortunately has been proven to be true.

Despite this, I do not agree with the above consensus. Although, on paper, I agree with CDC guidelines and in fact follow most of them. However, I do not believe that they should be imposed through statute. For example, these guidelines do not deal with so-called "legacy patients" who are utilizing very high MME and who pain specialists often "inherit" from primary care physicians who will no longer treat them. A pain specialist may agree with the MME recommendation but is continually bombarded with prior authorizations and refusals from insurance companies, along 
with a gauntlet of state regulations to provide care to these patients. For example, a patient who is taking $500 \mathrm{MME}$ daily may require a weaning schedule but cannot initiate at $90 \mathrm{MME} /$ day. Insurance companies routinely refuse to authorize $>100 \mathrm{MME}$ per day (20), therefore making it impossible to begin a logical weaning schedule and forcing the patient into withdrawal or into seeking a detoxification program.

Similarly, suppose one inherits a patient utilizing 500 $\mathrm{MME} /$ day and is successful weaning them down to $120 \mathrm{MME} /$ day. Despite trying to achieve the $90 \mathrm{MME}$ goal, the patient is unable to do so. Is the doctor therefore in violation of state statute or insurance regulation if they cannot achieve the $90 \mathrm{MME}$ goal, despite a $76 \%$ decrease in MME? Despite our advanced training in opioid therapy, CDC guidelines (intended for primary care physicians for the initiation of opioid therapy) are severely limiting pain specialists.

Regarding recommendation \#6, a 3-day initial supply of opioids is unacceptable for conditions that pain specialists routinely treat. I would suggest that 3 days of opioids for an acute compression fracture of the spine (while awaiting imaging and kyphoplasty) is woefully inadequate. This creates a real problem for patients in that logistically it is quite difficult to obtain appropriate imaging studies in 3 days, let alone get authorization for them. This results in repeat visits for additional prescriptions, which drives up the cost of health care.

Guidelines are exactly that. They are a set of recommendations based on the best level of evidence and they should not be "perverted" into insurance regulation or statutory language. The pain specialist is thus forced into a "cookbook approach" to opioid therapy. The question remains, do we really want the government in the exam room supervising our prescribing habits? Medicine should not be legislated.

IPM is a component of an integrated approach to chronic pain. Former Health and Human Services (HHS) Secretary Tom Price, MD, announced the creation of a new task force to develop best practices for prescribing pain medication and for managing chronic and acute pain.

The Pain Management Best Practices Inter-Agency Task Force, which was authorized by the Comprehensive Addiction and Recovery Action of 2016, is assigned the following responsibilities:
- Determining whether there are gaps or inconsistencies in pain management best practices among federal agencies

- Proposing recommendations on addressing gaps or inconsistencies

- Providing the public with an opportunity to comment on any proposed recommendations

- Developing a strategy for disseminating information about best practices.

It is anticipated that IPM will be a significant component of the plan suggested by committee members, despite the negative connotations promulgated in the CDC guidelines.

IPM is a major tool in treating chronic pain, and interventional pain specialists hailed the CDC guidelines as a victory for IPM. This meant that we would be able to provide more interventional pain management procedures in place of opioid therapy. Guess again. There are more restrictions on interventional pain techniques than ever before, and most recently, a troubling study (21) puts the use of radiofrequency rhizotomy at risk as well.

\section{Do we really need to limit supply to achieve the desired effect?}

In my opinion, the answer is no. Florida was decimated by prescription overdose deaths over the past 15 years and ultimately passed 3 rounds of legislation to curb this scourge. However, in our legislation the terms MME or limitations of dosing do not exist. Instead of reducing the supply (which is the easiest solution), Florida chose to elevate the standard of practice for all physicians to that of a pain management specialist. Consequently, every physician who prescribes controlled substances for the treatment of chronic non-cancer pain must register as a controlled substance prescriber and follow the legislation or risk significant penalties and fines (6-month loss of license and $\$ 10 \mathrm{~K}$ fine). The legislation closely resembles a Risk Evaluation and Mitigation Strategy program, which is what most pain specialists follow. Why shouldn't primary care physicians be held to the same standard of pain specialists when prescribing opioids for chronic pain?

The result of this legislation was greater than $55 \%$ reduction in prescription overdose deaths and a similar reduction in opioid prescribing. As expected, the shift to heroin and synthetic combinations occurred. 
If you squeeze the balloon in one spot, it only bulges in another.

States and the federal government should consider mandatory education for prescribers. The ASIPP Controlled Substance Management Course should serve as a model for this. The national database should be funded to track all prescribed controlled substances (National All Schedules Prescription Electronic Reporting Act; NASPER). Congress must fund NASPER, which was strongly supported by ASIPP and signed into law by President Bush in 2005. This law ensures that all states have a working data base which communicates with other states, to reduce doctor shopping and diversion of controlled substances.

Treatment options for opioid use disorder remain woefully inadequate. Senate Bill (SB 1455), Recovery Enhancement for Addiction Treatment Act, was passed in the summer of 2016 and loosened the restrictions on the number of patients a physician can treat with buprenorphine for opioid addiction. This ultimately led to the passage of The Comprehensive Addiction and Recovery Act (CARA) in July of 2016.

\section{Summary of Provisions of CARA}

- Expand prevention and educational efforts-particularly aimed at teens, parents and other caretakers, and aging populations - to prevent the abuse of methamphetamines, opioids, and heroin, as well as to promote treatment and recovery.

- Expand the availability of naloxone to law enforcement agencies and other first responders to help in the reversal of overdoses to save lives.

- Expand resources to identify and treat incarcerated individuals suffering from addiction disorders promptly by collaborating with criminal justice stakeholders and by providing evidence-based treatment.

- Expand disposal sites for unwanted prescription medications to keep them out of the hands of our children and adolescents.
- Launch an evidence-based opioid and heroin treatment and intervention program to expand best practices throughout the country.

- Launch a medication-assisted treatment and intervention demonstration program.

- Strengthen prescription drug monitoring programs to help states monitor and track prescription drug diversion and to help at-risk individuals access services.

- HHS subsequently lifted the previous cap of 100 to 275 patients that can be treated with buprenorphine for opioid use disorder.

In summary, the CDC guidelines have unintended consequences. They provide a template for legislatures and insurers to curtail opioid use at the expense of the doctor-patient relationship. However, the reduction in prescription opioid supply has failed to curtail overdose deaths. The deaths from illicit heroin and synthetic combinations continue to rise as the number of commonly prescribed opioids decreases. Many legitimate pain patients are suffering secondary to the fallout prescribed by the CDC guidelines.

The supply of heroin is abundant and cheap. The demand for this has never been adequately addressed and is grossly underestimated. The administration must empower law enforcement and border controls to stem the flow of heroin into the US. However, access to treatment remains woefully inadequate and poorly covered by insurers.

Instead, supply-siders continue to limit access to patients who benefit from these medications. The heroin deaths continue to rise. Our job as pain specialists has become even more difficult navigating the torrential flood of prior authorizations and statutory regulations. "The CDC guidelines are good for us, and we needed these more than ever." Be careful what you wish for...... 


\section{REFERENCES}

1. Jamison RN, Sheehan KA, Scanlan E, Matthews M, Ross EL. Beliefs and attitudes about opioid prescribing and chronic pain management: Survey of primary care providers. J Opioid Manag 2014; 10:375-382.

2. Dowell D, Haegerich TM, Chou R. CDC guideline for prescribing opioids for chronic pain - United States, 2016. MMWR Recomm Rep 2016; 65:1-49.

3. Rudd RA, Aleshire N, Zibbell JE, Gladden M. Increases in drug and opioid overdose deaths — United States, 2000-2014. MMWR 2015; 64:1378-1382.

4. Centers for Disease Control and Prevention. Number and ageadjusted rates of drug poisoning deaths involving opioid analgesics and heroin: United States, 2000-2014. www.cdc.gov/ nchs/data/health policy/AADR drug poisoning involving_OA Heroin_US_2000-2014.pdf. Date Accessed 08/30/2016.

5. Shuchat A Houry D, Guy GP Jr. New data on opioid use and prescribing in the United States. JAMA 2017; 315:425-426.

6. Mercado MC, Sumner SA, Spelke MB, Bohm MK, Sugerman DE, Stanley C. Increase in drug overdose deaths involving fentanyl-Rhode Island, January 2012-March 2014. Pain Med 2017; doi:10.1093/pm/pnx015. [Epub ahead of print].

7. Ives TJ, Chelminski PR, Hemmett-Stabler CA, Malone RM, Perhac JS, Potisek NM, Shilliday BB, DeWalt DA, Pignone MP. Predictors of opioid misuse in patients with chronic pain: A prospective cohort study. BMC Health Serv Res 2006; 6:46.

8. Turk DC, Swanson KS, Gatchel RJ. Predicting opioid misuse by chronic pain patients: A systematic review and literature synthesis. Clin J Pain 2008; 24:497-508.

9. Manchikanti L. Prescription drug abuse: What is being done to address this new drug epidemic? Testimony before the Subcommittee on Criminal Justice, Drug Policy and Human Resources. Pain Physician 2006; 9:287-321.

10. Kouyanou K, Pither CE, Wessely S. Medication misuse, abuse and dependence in chronic pain patients. J Psychosom Res 1997; 43:497-504.

11. New NICE quality standard aims to improve recognition, assessment and availability of treatments for anxiety disorders. www. nice.org.uk/guidance/qs53/documents/new-nice-quality-standard-aims-to-improve-recognition-assessment-and-availabilityof-treatments-for-anxiety-disorders. Date Accessed 10/6/2017.

12. Craig T. Mallak, MD, JD; Chief, Office of the Medical Examiner and Trauma Services, Broward County; Personal Communication.
13. Manchikanti L, Kaye AM, Knezevic NN, McAnally $H$, Slavin K, Trescot AM, Blank S, Pampati V, Abdi S, Grider JS, Kaye AD, Manchikanti KN, Cordner H, Gharibo CG, Harned ME, Albers SL, Atluri S, Aydin SM, Bakshi S, Barkin RL, Benyamin RM, Boswell MV, Buenaventura RM, Calodney AK, Cedeno DL, Datta S, Deer TR, Fellows B, Galan V, Grami V, Hansen $H$, Helm li S, Justiz R, Koyyalagunta D, Malla Y, Navani A, Nouri KH, Pasupuleti R, Sehgal N, Silverman SM, Simopoulos TT, Singh V, Solanki DR, Staats PS, Vallejo R, Wargo BW, Watanabe A, Hirsch JA. Responsible, safe, and effective prescription of opioids for chronic non-cancer pain: American Society of Interventional Pain Physicians (ASIPP) Guidelines. Pain Physician 2017; 20:S3-S92.

14. Gaskin DJ, Richard P. The economic costs of pain in the United States. J Pain 2012; 13:715-724.

15. The National Academies Press, Washington, DC, June 29, 2011. www.iom.edu/ /media/Files/Report\%20Files/2011/Relieving-Pain-inAmerica-A Blueprint-for-Transforming PreventionCare-Education Research/Pain\%20Research\%202011\%20Report\%20Brief.pdf. Date Accessed 10/8/2017.

16. Curtin SC, Warner M, Hedegaard $H$. Increase in suicide in the United States, 1999-2014. NCHS Data Brief, No. 241. Hyattsville, MD: National Center for Health Statistics. 2016. www. cdc.gov/nchs/products/databriefs/db241.htm. Date Accessed 10/6/2017.

17. Dunn KM, Saunders KW, Rutter CM, Banta-Green CJ, Merrill JO, Sullivan MD, Weisner CM, Silverberg MJ, Campbell Cl, Psaty BM, Von Korf M. Opioid prescriptions for chronic pain and overdose: A cohort study. Ann Intern Med 2010; 152:85-92.

18. Gomes T, Mamdani MM, Dhalla IA, Paterson JM, Juurlink DN. Opioid dose and drug-related mortality in patients with nonmalignant pain. Arch Intern Med 2011; 171:686-691.

19. Bohnert AS, Valenstein M, Bair MJ, Ganoczy D, McCarthy JF, Ilgen MA, Blow FC. Association between opioid prescribing patterns and opioid overdose-related deaths. JAMA 2011; 305:1315-1321.

20. Redacted prior authorization- denial, UnitedHealthcare, personal communication from Dr. Miguel De La Garza.

21. Juch JNS, Maas ET, Ostelo RWJG, Groeneweg JG, Kallewaard JW, Koes BW, Verhagen AP, van Dongen JM, Huygen FJPM, van Tulder MW. Effect of radiofrequency denervation on pain intensity among patients with chronic low back pain: The Mint Randomized Clinical Trials. JAMA 2017; 318:68-81. 